\title{
EXPERIMENTAL AND COMPUTATIONAL STUDIES OF CIRCULATING FLUIDIZED BED
}

\author{
ALI MORADI, NASTARAN AHMADPOUR SAMANI, MASIH MOJARRAD, MOHAMMAD SHARFUDDIN, \\ JANITHA C. BANDARA \& BRITT M. E. MOLDESTAD \\ University of South-Eastern Norway, Norway.
}

\begin{abstract}
Biomass gasification represents an efficient process for the production of power, heat and biofuels. Different technologies are used for gasification and this article focuses on a circulating fluidized bed (CFB) system. Understanding the behaviour of particles is of primary importance and a cold flow CFB experimental unit was constructed and tested. The particle circulation rate is greatly affected by the loop seal performance, and therefore the loop seal should be properly optimized to maintain an uninterrupted operation. Smooth flow regimes were obtained for the CFB by varying the loop seal aeration rates. Particles with size $850-1000 \mu \mathrm{m}$ and $1000-1180 \mu \mathrm{m}$ were chosen for the experiments. The minimum flow rates of air into the riser for the two particle sizes were found to be 1.3 and $1.5 \mathrm{Sm}^{3} /$ min, respectively. To obtain a smooth flow regime, a velocity range for aeration in the loop seal was found for the two particle sizes. Based on the experimental results, combinations of flow rates were suggested for the simulations. A Computational Particle Fluid Dynamic (CPFD) model was developed using Barracuda VR, and the model was validated against experimental results. The simulated results for the system regarding the pressure and the height of the bed material in the standpipe agreed well with the experimental results. The deviation between the experimental and computational pressure was less than $0.5 \%$ at all the locations for both the particle sizes. The deviation in particle level was about $6 \%$ for the $850-1000 \mu \mathrm{m}$ particles and $17 \%$ for the $1000-1150 \mu \mathrm{m}$ particles. Both the experiments and the simulations predicted that a small fraction of the circulating sands are emitted from the top of the rig. The validated CPFD model was further used to predict the flow behaviour and the particle circulation rate in the CFB.

Keywords: Baracuda, circulating fluidized bed, CPFD, gasification, loop seal, multiphase flow.
\end{abstract}

\section{INTRODUCTION}

Consumption of energy is increasing rapidly worldwide and the expansion of renewable energy sources is needed. Scientists are working on the development of technologies and logistics related to energy extraction from renewable sources. Fluidized bed is a promising technology in biomass gasification and combustion due to good mixing capacity, which gives a high mass and energy transfer with uniform temperature over the gasifier. There are several potential configurations of fluidized bed reactors applicable for industrial operations. Circulating fluidized bed (CFB) is one of the technologies, which has come into the limelight during the previous two decades due to its extensive applications. CFB has been recently used in the combustion process, fluid catalytic cracking in petroleum refineries, gasification of coal and biomass, chemical synthesis, removal of pollutants, etc. [1]. The advantages of CFB gasification is that it has relatively low tar production, high degree of conversion, reduced residence time and good ability to scale-up.

A typical setup for a CFB reactor is presented schematically in Fig. 1. The CFB operates at the fast fluidization regime and consists of a riser, a cyclone, a downcomer and a gas-sealing mechanism such as a loop seal. The loop seal is a type of particle flow control valves designed for recycling of the particles back to the riser with a proper control. In the riser, the particles are fluidized by introduction of a fluid with a higher velocity than the particle terminal velocity. The fluid is fed from the bottom of the reactor. The loop seal is also needed to 
aerate to keep the particle phase in fluidized conditions (i.e. over minimum fluidization). An efficient and safe design of CFB systems requires accurate predictions of the gas-particle behaviour at different process conditions. The rate of particle circulation is one of the most important parameters in any CFB system [2]. The application of the CPFD numerical method to simulate a CFB with a loop seal has been previously studied by Wang et al. [3] and Bandara et al. [4]. The aim of their studies was to investigate the influence of the rate of loop seal aeration, fluidized air velocity in the riser and the total bed inventory on the particle circulation properties.

In this work, experimental studies of a CFB are performed to obtain a better understanding of the particle behaviour under varying loop seal and riser aeration conditions. The results will help to find smooth operational regimes for the CFB. The experiments were performed using sand particles as the bed material and air as the fluidizing fluid. Sand is often used as bed material in fluidized bed reactors. The bed material is used to ensure good mixing of the fuel and the fluidizing gas in the reactor, and to enhance the mass and energy transfer. In a biomass CFB reactor, the biomass reacts very fast with the gas, producing a synthesis gas and char. Unreacted char will follow the sand particles through the cyclone, the standpipe, the loop seal and back to the riser. The circulation behaviour will mainly be controlled by the sand particles and very little by the char, and using sand in the experiments and simulations will give a good indication of the flow behaviour in the CFB. This article includes both experimental results and development of a Computational Particle Fluid Dynamic (CPFD) model to predict particle distribution at different positions in the CFB system, circulation

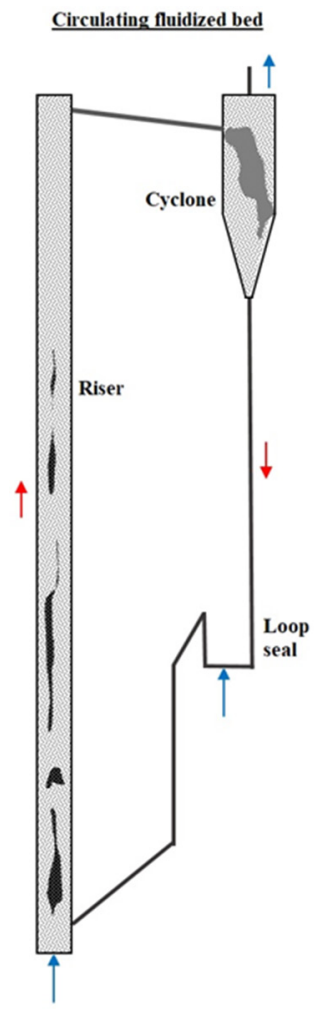

Loop seal operation
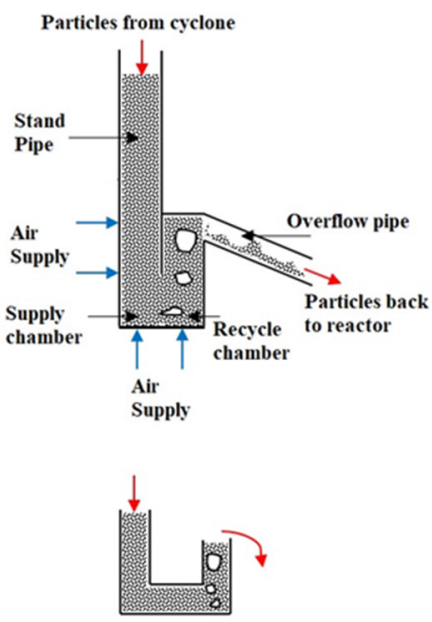

Figure 1: CFB system. 
rates and pressure profiles. The CPFD simulation results were compared against experimental data.

\section{MATERIALS AND METHODS}

\subsection{Experimental setup}

The schematic of the CFB used for experiments is shown in Fig. 2. The inside diameter of the riser is $54 \mathrm{~mm}$ whereas the cyclone riser connections are constructed with $34 \mathrm{~mm}$ Plexiglas pipes. The riser stands $2300 \mathrm{~mm}$ high from the bottom gas-distributor plate. The horizontal section of the loop seal is a $34 \times 34 \mathrm{~mm}$ section box with $100 \mathrm{~mm}$ in length. There are three fluid inlets to the CFB: the first in the bottom of the riser (FR1), the second in the bottom of the loop seal (FR2) and the third in the right-hand side of the loop seal standpipe (FR3).

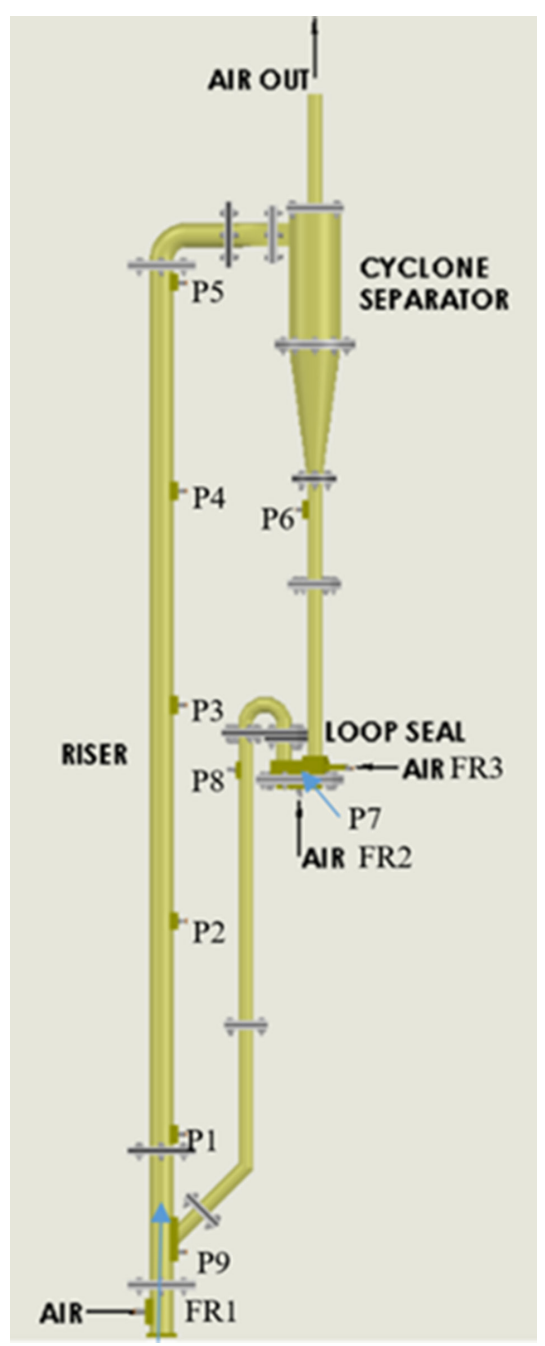

Figure 2: CAD drawing from SolidWorks of the experimental setup of CFB. 
Sand with density $2650 \mathrm{~kg} / \mathrm{m}^{3}$ was used as the particle phase while the fluidizing gas was air. Initially, $520 \mathrm{~mm}$ of sand was filled into the loop seal and led to the riser by aerating FR2 and FR3. The flow rate of FR1 was gradually increased until the particles are conveyed to achieve a steady circulation of particles.

The aim of this study is to find the range of flow rates that can be used for FR2 and FR3, and the minimum flow rate of FR1. The minimum flow of FR1 is referred to as the velocity that maintains a steady flow in the riser, whereas the maximum flow is decided by the increasing amount of particles escaping with the cyclone gas outflow. Above the maximum velocity, the level of the sand in the standpipe became unstable and fluctuated considerably. For this purpose, FR3 was fixed at a very high flow rate (about $0.06 \mathrm{Sm}^{3} / \mathrm{min}$ ) and FR2 was increased smoothly from zero until the sands started entering the riser. At that velocity, the minimum velocity for FR2 was observed and recorded. In the next step, FR2 was set at the recorded minimum value and FR3 was increased gradually from zero until the sand started to circulate. Then FR3 was increased by a step of $0.004 \mathrm{Sm}^{3} / \mathrm{min}$ until the level of sand in the standpipe started to fluctuate. During the steady-state operation at each velocity, the system pressure and the flow rates of the sand inside the standpipe were recorded. To determine the flow rate of sand, FR2 and FR3 were closed and immediately the increasing sand level in the standpipe during a known time was observed and recorded. The sand flow rate was calculated from:

$$
F R_{p}=\frac{A_{s} \cdot h}{t} \times \text { bulk density }\left(\frac{\mathrm{kg}}{\mathrm{s}}\right)
$$

where $F R_{p}$ is the flow rate of the sand inside the standpipe, $A_{s}$ is the surface area of the pipe $\left(9.0746 \mathrm{~cm}^{2}\right), h$ is the height of the accumulated particles in the standpipe and $t$ is the time.

\subsection{Development of a CPFD model}

The CPFD model was developed in the Barracuda VR 17.3.0 commercial CFD code. The fluid domain is crucial for the calculations, and therefore the interior dimensions of the experimental unit were measured carefully. The model for the fluid domain was developed in the SolidWorks platform and was imported into CPFD in STL file format. Subsequently, the fluid domain was captured into the computational grid using the grid generation tool. The grid resolution is a key parameter for the accuracy and meets the convergence of numerical calculation. Moreover, the wall boundaries, internal solid features, such as parcel resolution, and the boundary surfaces are also affected by the grid configuration in CPFD. Figure 3 illustrates the generated grid over different sections of the CFB system. The grid resolution should be

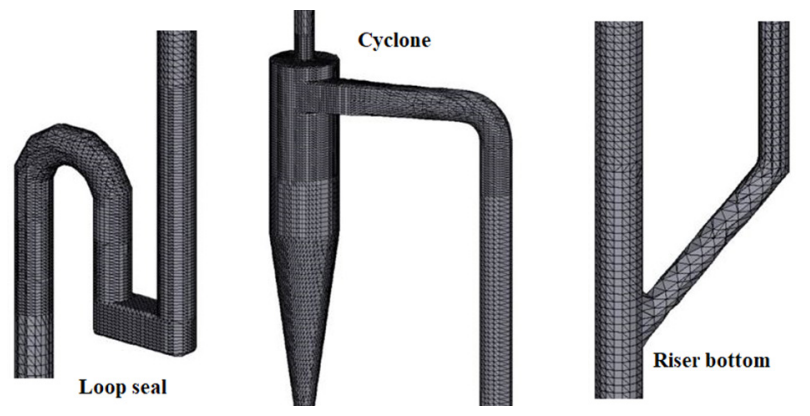

Figure 3: Grid generation for CPFD modelling. 
optimized with respect to accuracy and computational time, and the higher the number of cells the longer the computational time. For particle systems, there are limitations to the grid resolution, where the cell size should be several times larger than the size of the largest particles in the system. According to the studies of Bandara et al. [4], the grid resolution at the loop seal is the most crucial. Therefore, the loop seal grid was refined to the maximum extent, keeping an acceptable cell size to particle size ratio.

Fluid drag is the main force acting on the particles, and the general format of the drag force is expressed as:

$$
F_{p}=m_{p} D\left(u_{f}-u_{p}\right)
$$

where $m_{p}$ is the mass of particles, $u_{f}$ is the fluid velocity, $u_{p}$ is the particle velocity and $D$ is the drag coefficient. Several in-built drag models are available in the Barracuda package, and detailed information about different drag models with references are discussed in the Barracuda manual [5]. Previous results from CPFD simulations of bubbling fluidized bed gasifiers have shown a good agreement with experimental data when the Wen-Yu drag model was used [6-8]. Furthermore, simulations of CFB systems [4, 9] have also shown better results with Wen-Yu/Ergun drag model, and therefore it was used in this study. The Wen-Yu/ Ergun drag model covers the whole range of particle volume fractions where the Ergun drag model is proved excellent for dense phase systems and the Wen-Yu model is appropriate for dilute systems. Chen et al. tested different drag models in a CPFD scheme and the results indicated that the drag force is overestimated, although the cumulative method used to compute drag force is more accurate than the proportional method in the two-fluid model [10]. The Wen-Yu/Ergun drag coefficient is used when the gas volume fraction is higher than 0.8 and it is given by:

with

$$
D_{W e n-Y u}=\frac{3}{8} C_{d} \frac{\rho_{g}}{\rho_{p}} \frac{\left|u_{g}-u_{p}\right|}{r_{p}} a^{-2.65}
$$

$$
\begin{gathered}
C_{d}=\frac{24}{R_{e}},\left(R_{e}<0.5\right) \\
C_{d}=\frac{24}{R_{e}}\left(1+0.115 R_{e}^{0.687}\right),\left(0.5 \leq R_{e} \leq 1000\right) \\
C_{d}=0.4,\left(R_{e}>1000\right)
\end{gathered}
$$

where $C_{d}$ is the drag coefficient, $R_{e}$ is the Reynolds number and $r_{p}$ is the particle diameter. As the gas volume fraction decreases below 0.8, the Ergun correlation is used:

$$
D_{\text {Ergun }}=0.5\left(\frac{C_{1} a_{p}}{a_{g} R_{e}}+C_{2}\right) \frac{\rho_{g}}{\rho_{p}} \frac{\left|u_{g}-u_{p}\right|}{r_{p}}
$$

The default values for the laminar and turbulent coefficients in the Barracuda $\mathrm{VR}^{\circledR}$ are $C_{1}=180$ and $C_{2}=2.0$. The particle modelling parameter values were adopted from the work of Bandara et al. [4].

Establishment of boundary conditions is the succeeding step after the grid generation. The gas out from the cyclone was defined as a pressure boundary with provisions for particle escaping. The riser and the loop seal aerations were implemented as flow boundaries. Figure 4 illustrates the boundary conditions and the initial particle filling in the standpipe, which is identical with the experimental procedure. The rate of particle circulation and the rate of 

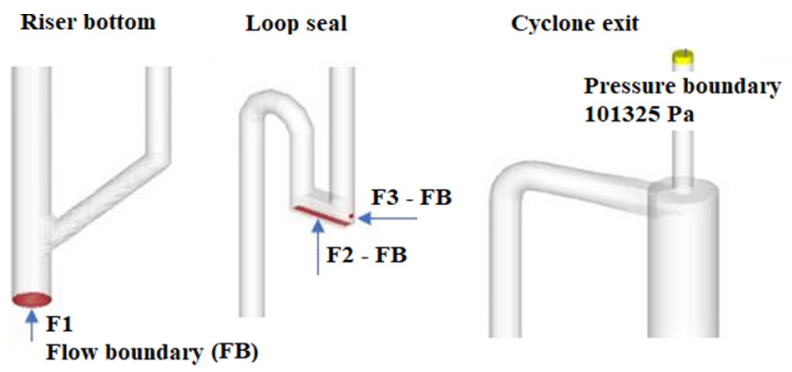

Figure 4: Boundary conditions.

particle escape from the cyclone are monitored using flux planes. Transient data points were used to log the system pressure at identical locations as in the experimental rig.

In addition to the grid resolution, the numerical scheme and the calculation time step are important to obtain accurate simulation results. Smaller time steps give more accurate solutions, but require a longer simulation time. Consequently, there is a trade-off between accuracy and calculation time. As a result, the time steps have to be defined so that the accuracy is sufficient and the calculation time is reasonable. Based on the experience, the time steps were set to $0.005 \mathrm{~s}$. The time duration of the simulation was chosen as $45 \mathrm{~s}$, which was sufficient to ensure that the system reaches steady-state conditions. The partial donor cell numerical scheme was used, which is a weighted average hybrid of central difference and upwind schemes. The large eddy simulation (LES) was used to model the turbulence prevailing at higher length scales, whereas the Smagorinsky model guarantees the capturing of subgrid scale turbulences.

\section{RESULTS AND DISCUSSION}

The results from the simulations and comparison between simulations and experiments are presented in this section. The rate of particle circulation, system pressure and particle bed height at the standpipe were used for the comparison. Gas velocities practiced in the riser section were well above the particle terminal velocity. The particle overflow from the loop seal is not uniform, and instead it delivers particle clusters. Therefore, at lower velocities, these clusters travel along the riser unbroken, impact at the bend of the riser exit and partly accumulate at the riser-cyclone connecting section. Smaller particles have a high tendency to travel as clusters along the riser. In the experimental tests with the smaller particles, interruptions occurred due to static charges. On the other hand, higher velocities inside the riser increase the turbulence, and consequently the clusters are dispersed, which was an advantageous dimension of the used high velocities in the riser.

\subsection{Experimental results}

Several particle sizes were tested, but due to the problem with electrostatic charge, particles with size $850-1000 \mu \mathrm{m}$ and $1000-1180 \mu \mathrm{m}$ were chosen for the experiments. The minimum flow rates of air into the riser (FR1) for these two particle sizes were found to be 1.3 and 1.5 $\mathrm{Sm}^{3} / \mathrm{min}$, respectively. The ranges of flow rates of gas injection from the bottom of the loop seal (FR2) were found to be $0.012-0.056 \mathrm{Sm}^{3} / \mathrm{min}$ for the smallest particles and $0.014-0.058$ $\mathrm{Sm}^{3} / \mathrm{min}$ for the largest particles. The respective flow rate ranges for FR3 in the loop seal were found to be $0.006-0.048 \mathrm{Sm}^{3} / \mathrm{min}$ and $0.01-0.056 \mathrm{Sm}^{3} / \mathrm{min}$. Based on the experimental results, combinations of flow rates were suggested for the simulations. The properties for the 
Table 1: Particle density, particle size range and air flow rates suggested for the simulations.

\begin{tabular}{llllll}
\hline $\begin{array}{l}\text { Simulation } \\
\text { cases }\end{array}$ & $\begin{array}{l}\text { Particle size } \\
{[\boldsymbol{\mu m}]}\end{array}$ & $\begin{array}{l}\text { Bulk density } \\
{\left[\mathbf{k g} / \mathbf{m}^{3}\right]}\end{array}$ & $\begin{array}{l}\text { FR1 }\left[\mathbf{S m}^{3} /\right. \\
\text { min] }\end{array}$ & $\begin{array}{l}\text { FR2 }\left[\mathbf{S m}^{3} /\right. \\
\text { min }]\end{array}$ & $\begin{array}{l}\text { FR3 }\left[\mathbf{S m}^{3} /\right. \\
\text { min] }\end{array}$ \\
\hline Simulation 1 & $850-1000$ & 1377 & $1.3(9.5 \mathrm{~m} / \mathrm{s})$ & 0.016 & 0.044 \\
Simulation 2 & $850-1000$ & 1377 & $1.3(9.5 \mathrm{~m} / \mathrm{s})$ & 0.028 & 0.030 \\
Simulation 3 & $850-1000$ & 1377 & $1.3(9.5 \mathrm{~m} / \mathrm{s})$ & 0.052 & 0.016 \\
Simulation 4 & $1000-1180$ & 1390 & $1.5(11 \mathrm{~m} / \mathrm{s})$ & 0.018 & 0.048 \\
Simulation 5 & $1000-1180$ & 1390 & $1.5(11 \mathrm{~m} / \mathrm{s})$ & 0.032 & 0.030 \\
Simulation 6 & $1000-1180$ & 1390 & $1.5(11 \mathrm{~m} / \mathrm{s})$ & 0.054 & 0.020 \\
\hline
\end{tabular}

particles used in the experiments and the selected combinations of the flow rates suggested for the simulations are given in Table 1.

In the experimental tests, the only results that could be measured with high accuracy were particle level in the standpipe and the pressure profile over the CFB. These results are presented in Section 3.2 together with the simulation results, and they are used to validate the CPFD model. Predicting the flow rate of particle circulation by stopping the circulation and observing the increase of particles in the standpipe over a certain time was also tried. However, due to uncertainties in the measurements, these experimental results are not used for validation of the CPFD model. One reason is that the gas distributor plate does not function in a manner exactly similar to the uniform gas distribution implemented in the simulations. Another reason is that an occasional particle layer is created at the inside surface of the standpipe bottom due to static charges. This narrows down the cross-sectional area for the particles to descend. Finally, the measurements of particle circulation rate in the simulations are performed during the steady-state operation without interrupting the process. It was observed that a fraction of the circulating sand particles was transferred with the gas out of the CFB via the cyclone.

\subsection{Validation of CPFD model}

Figure 5 shows a comparison between experimental and simulation results regarding the particle level in the standpipe for Simulations 3 and 6. Simulation 3 was performed with

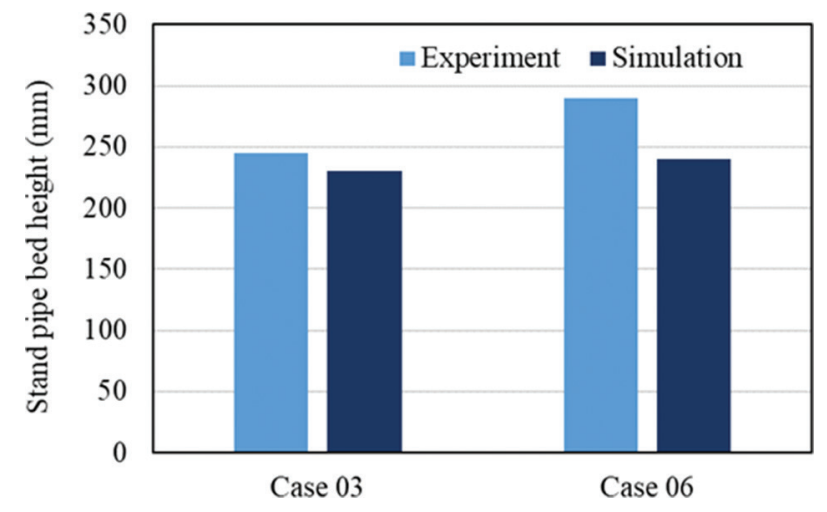

Figure 5: Comparison between experimental and simulation results. 
$850-1000 \mu \mathrm{m}$ particles, and the flow rates FR2 and FR3 were 0.052 and $0.016 \mathrm{Nm}^{3} / \mathrm{min}$, respectively. Simulation 6 was carried out using 1000-1150 $\mu \mathrm{m}$ particles, and the flow rates FR2 and FR3 were set to 0.054 and $0.020 \mathrm{Nm}^{3} / \mathrm{min}$, respectively. The simulations give slightly higher particle levels than the experiment. The deviations between the experimental and computational levels are about $6 \%$ for the $850-1000 \mu \mathrm{m}$ particles and $17 \%$ for the $1000-1150 \mu \mathrm{m}$ particles. A wire was installed inside the experimental standpipe to prevent particles from sticking to the wall due to electrostatic forces. The wire reduces the volume of the pipe slightly and thereby increases the level of the particles. Furthermore, there may be a slight difference in the bubbling behaviour between experiments and simulations, which consequently may cause the deviated results for the bed height. However, the level of agreement between the results from the experiments and the simulations is acceptable.

In Figs. 6 and 7, the pressure profiles along the CFB are presented for particles with size 850-1000 and 1000-1150 $\mu \mathrm{m}$, respectively. The comparison shows good agreement between the computational and the experimental results for both types of particles. The deviation is $<0.5 \%$ at all the locations. The particle attrition is a common problem, and therefore the particle size distribution may change with time. As a result, the system pressure and rate of particle circulation can change with time, which is not captured by the simulations.

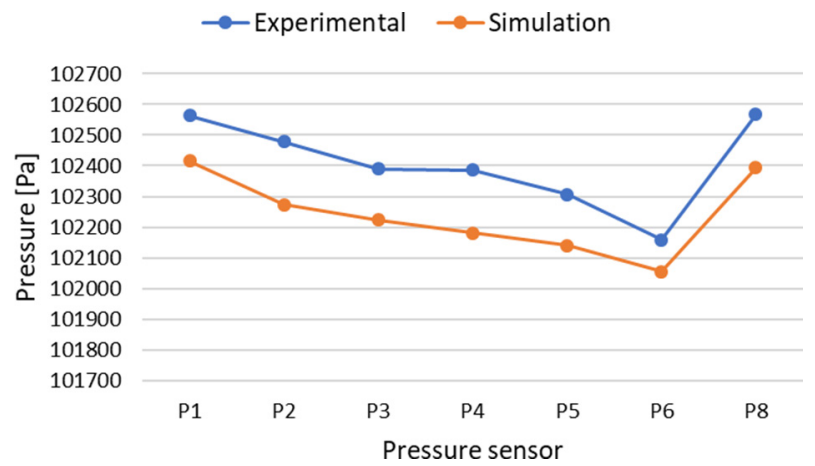

Figure 6: Comparison of computational and experimental pressures along the CFB for 850 $1000 \mu \mathrm{m}$ particles.

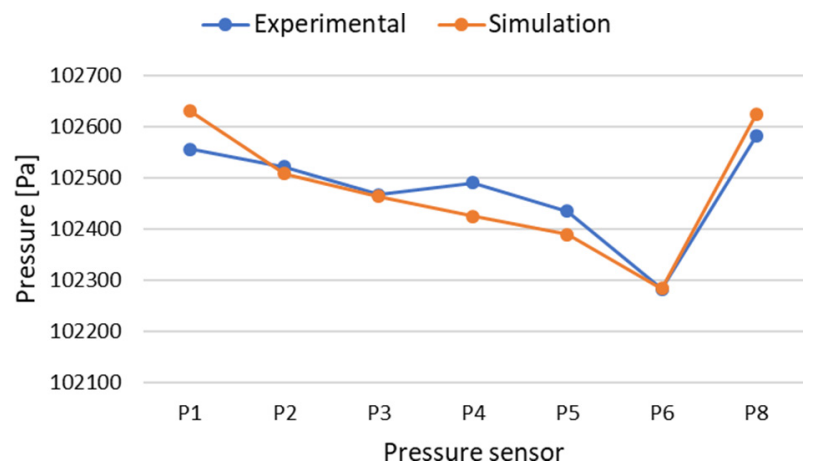

Figure 7: Comparison of computational and experimental pressures along the CFB for 1000$1150 \mu \mathrm{m}$ particles. 


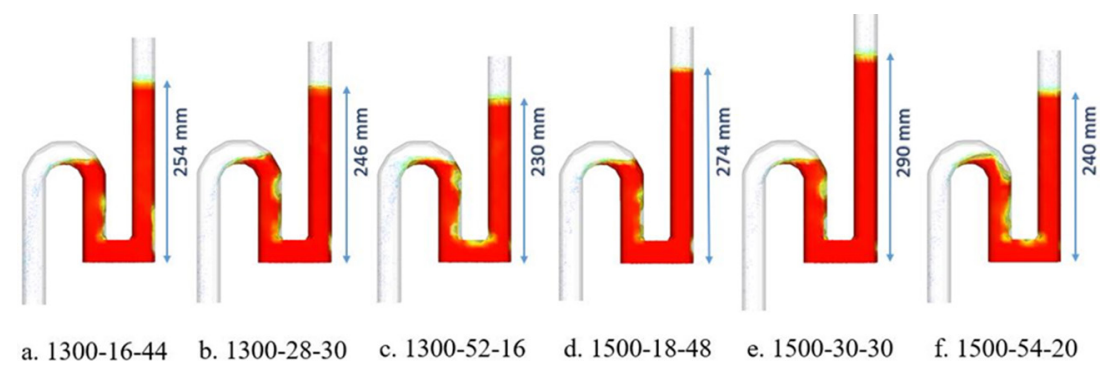

Figure 8: Level of particles in the downcomer.

\subsection{CPFD simulation results}

The validated CPFD model was further used to study the hydrodynamics, the pressure profiles and fluctuations, the circulation rates and the loss of particles from the CFB rig via the exit of the cyclone. The simulations were performed for six different cases.

\subsubsection{Particle hydrodynamics and height in standpipe}

Figure 8 illustrates the level of sand particles in the downcomer at steady-state conditions for different air flow rates. The level of the particle gives a rough understanding about the particle distribution across the system. Reduced heights in the standpipe represent high particle loading in the riser and vice versa.

Figure 9 shows the volume fraction of sand particles in the CFB at steady-state condition for the different cases. Although particle volume fractions could not be measured accurately in the experiments, a slightly high concentration of particles at the cyclone bottom and the riser bottom as shown in Fig. 9 was observed in the experiments as well. Furthermore, the figure illustrates that the bubble rise occurs close to the recycle pipe at the inner wall of the loop seal. The same bubble location was observed in the experiments.

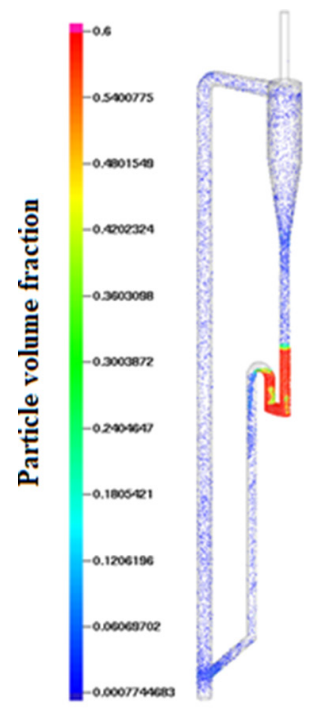

Case 01

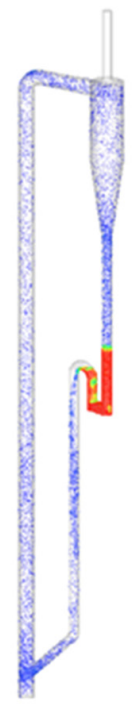

02

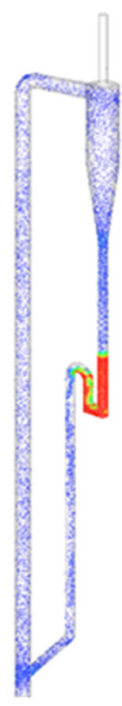

03

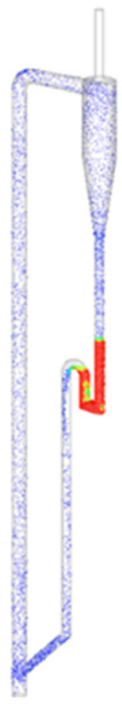

04

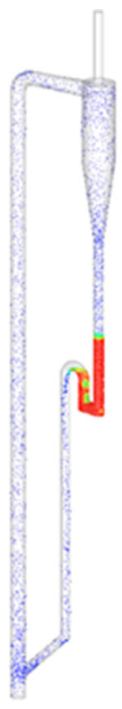

05

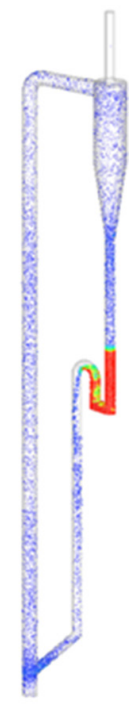

06

Figure 9: Volume fraction of sand particles at steady-state condition. 


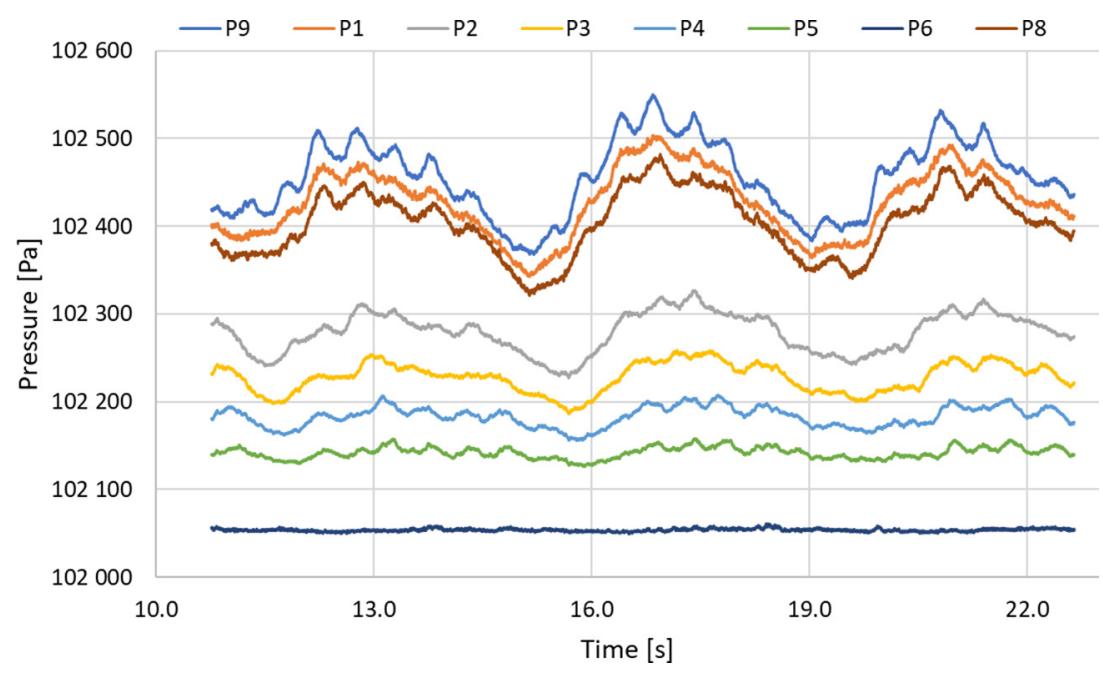

Figure 10: Pressure variation versus time at different positions in the CFB.

\subsubsection{System pressure}

Figure 10 shows the pressure and pressure variations during the simulations at different positions in the rig as a function of time for Case 1. The observation is done for the time interval 10-25 s, when the CFB system was running at steady-state conditions. According to the figure, the time-evolved pressure variation is high for P8, P9 and P1, which represent the loop seal outflow, the loop seal-riser connection and the loop seal bottom, respectively. As particle clusters are fed out of the loop seal and as the clusters continue towards the riser bottom, the flow rate of the particle is highly varied. This may be the most likely cause of the high fluctuations in pressure. However, the clusters are broken as they travel along the riser and the flow is becoming more homogeneous. Therefore, the pressure, P2-P5, is getting uniform towards the top of the riser.

The average pressure drop at the different positions in the riser is illustrated in Fig. 11. The pressure decreases gradually with a uniform gradient from P2 to P5.

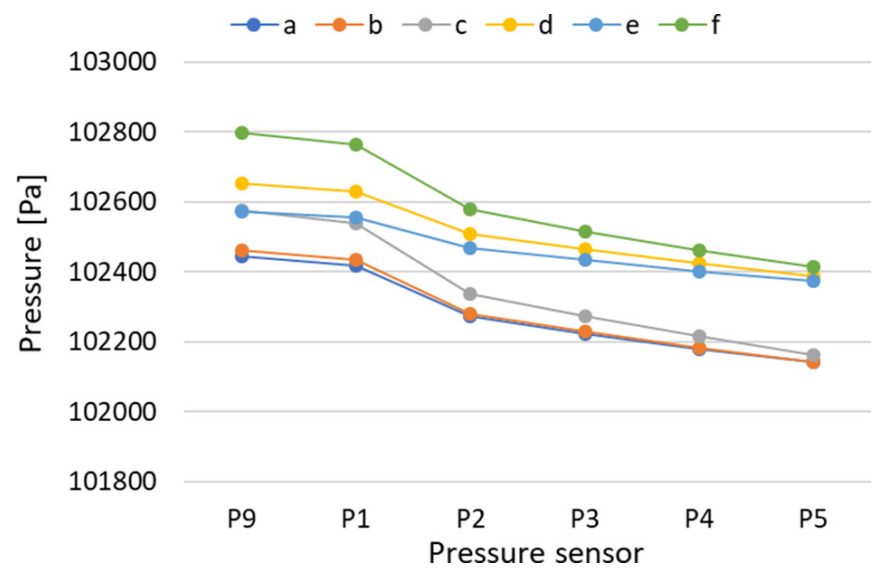

Figure 11: Average pressure drop along the riser of the rig. 
Table 2: Particle circulation and particle loss: results from CPFD simulations.

\begin{tabular}{lll}
\hline Simulation case & Mass flow rate of particle circulation $[\mathrm{kg} / \mathbf{s}]$ & Particle loss [kg/s] \\
\hline Simulation 1 & 0.031 & $7.76 \mathrm{E}-05$ \\
Simulation 2 & 0.034 & $9.83 \mathrm{E}-05$ \\
Simulation 3 & 0.047 & $1.34 \mathrm{E}-04$ \\
Simulation 4 & 0.023 & $1.00 \mathrm{E}-04$ \\
Simulation 5 & 0.015 & $6.06 \mathrm{E}-05$ \\
Simulation 6 & 0.041 & $1.59 \mathrm{E}-04$ \\
\hline
\end{tabular}

\subsubsection{Rate of particle circulation}

To investigate the mass flow rate of particle circulation and particle loss, the average values for these variables have been calculated by using the flux plane data files in Barracuda. Table 2 presents the mass flow rates of particles for all the six simulation cases. It was observed that the FR3 had a greater effect in improving the rate of particle circulation FR2. Simulations 3 and 6 have the highest air flow rates for FR3, which owned the highest rate of circulation. However, the rate of particle circulation from the simulation showed accountable variations from the experiments. Some improvements of the experimental rig are needed to enable accurate measurements regarding particle circulation and particle ejection.

\section{CONCLUSION}

A CFB is studied to find the gas velocities that give smooth operational conditions. Experiments and CPFD simulations were carried out for this purpose. For the experiments, silica sand was selected as the particle phase. Several particle sizes were tested, but due to the problem with electrostatic charge, particles with size $850-1000 \mu \mathrm{m}$ and $1000-1180 \mu \mathrm{m}$ were chosen for further experiments and simulations. The minimum flow rates of air into the riser (FR1) for these two particle sizes were found to be 1.3 and $1.5 \mathrm{Sm}^{3} / \mathrm{min}$, respectively. The ranges of flow rates of gas injected from the bottom of the loop seal (FR2) were found to be $0.012-0.056 \mathrm{Sm}^{3} / \mathrm{min}$ for the smallest particles and $0.014-0.058 \mathrm{Sm}^{3} / \mathrm{min}$ for the largest particles. The respective flow rate ranges for FR3 in the loop seal were found to be $0.006-0.048 \mathrm{Sm}^{3} / \mathrm{min}$ and $0.01-0.056 \mathrm{Sm}^{3} / \mathrm{min}$. The pressure in the riser decreased with the increasing flow rate. The level of sand in the standpipe decreased with increasing flow rate.

A CPFD model was established using the commercial simulation software Barracuda VR. The simulations were carried out for some selected experiments. Comparison between the simulations and the experimental results showed good consistency regarding pressures along the riser and the level of the sand particles in the standpipe. The deviation between the experimental and computational pressure was $<0.5 \%$ at all the locations for both particle sizes. The deviation in particle level was about $6 \%$ for the $850-1000 \mu \mathrm{m}$ particles and $17 \%$ for the $1000-1150 \mu \mathrm{m}$ particles. The accuracy in the experimental results regarding circulating rate of particles was considered to be low, and the results were therefore not used to validate the CPFD model. Both the experiments and the simulations predicted a small loss of the circulating sand particles via the outflow from the cyclone. The validated CPFD model was used to predict the particle circulation rates and the flow behaviour in the CFB at different operational conditions. 


\section{REFERENCES}

[1] Grace, J.R. \& Bi, H., Introduction to circulating fluidized beds. Circulating Fluidized Beds, Springer, pp. 1-20, 1997.

[2] Klenov, O.P., Noskov, A.S. \& Parahin, O.A., Investigation of behaviors in circulating fluidized bed. Chemical Engineering Science, 329, pp. 66-76, 2017. https://doi. org/10.1016/j.cej.2017.06.092

[3] Wang, Q., Wang, P., Yang, H., Lu, J., Liu, Q., Zhang, H., Wei, L. \& Zhang, M., Application of CPFD method in the simulation of a circulating fluidized bed with a loop seal Part II-Investigation of solids circulation. Powder Technology, 253, pp. 822-828, 2014. https://doi.org/10.1016/j.powtec.2013.11.040

[4] Bandara, J.C., Thapa, R., Nielsen, H.K., Moldestad, B.M.E. \& Eikeland, M.S., Circulating fluidized bed reactors - Part 01: Analyzing the effect of particle modelling parameters in Computational Particle Fluid Dynamic (CPFD) simulation with experimental validation. Particulate Science and Technology, 2019, doi:10.1080/02726351.2019.16 97773

[5] CPFD Software. LLC, "Barracuda VR Series 15," User Manual.

[6] Jaiswal, R., Furuvik, N.C.I.S., Thapa, R.K. \& Moldestad, B.M.E., Method of identifying an operating regime in a bubbling fluidized bed gasification reactor. International Journal of Energy Production \& Management, 5(1), pp. 24-34, 2020. https://doi. org/10.2495/eq-v5-n1-24-34

[7] Furuvik, N.C.I.S., Jaiswal, R., Thapa R.K. \& Moldestad, B.M.E., CPFD model for prediction of flow behavior in an agglomerated fluidized bed gasifier. International Journal of Energy Production and Management, 4(2), pp. 105-114, 2019. https://doi. org/10.2495/eq-v4-n2-105-114

[8] Furuvik, N.C.I., Jaiswal, R., Thapa, R.K. \& Moldestad, B.M.E., Study of agglomeration in fluidized bed gasification of biomass using CPFD simulations. Linköping Electronic Conference Proceedings, 170, pp. 176-181, 2019.

[9] Thapa, R.K., Frohner, A., Tondl, G., Pfeifer, C. \& Halvorsen, B.M., Circulating fluidized bed combustion reactor: Computational Particle Fluid Dynamic model validation and gas feed position optimization. Computers \& Chemical Engineering, 92, pp. 180-188, 2016. https://doi.org/10.1016/j.compchemeng.2016.05.008

[10] Chen, C., Werther, J., Heinrich, S., Qi, H.-Y. \& Ulrich, E., CPFD simulation of circulating fluidized bed risers. Powder Technology, 235, pp. 238-247, 2013. https://doi. org/10.1016/j.powtec.2012.10.014 